\title{
V.Yu.Mishin
}

\section{On contradictions in clinical guidelines on chemotherapy of patients with pulmonary tuberculosis in Russian Federation according to evidence-based medicine: meta-analysis and systematic review}

State Institution A.I.Evdokimov Moscow State Medical University, Healthcare Ministry of Russia; Moscow, Russia

\section{Summary}

Aim. The aim of this study was an analysis of published data in order to develop evidence-based clinical recommendations on chemotherapy of newly diagnosed pulmonary tuberculosis with high primary and secondary multidrug resistance.

Methods. Metaanalysis and systematic review was carried out of all published randomized clinical trials on this topic.

Results. Several experimental, bacteriological and clinical trials, which had performed in 1998-2003, showed a high efficacy of fluoroquinolones in patients with newly diagnosed pulmonary tuberculosis; a new effective chemotherapeutic regimen for regions with high rate of multi-drug resistant tuberculosis was developed and could be administered before results of drug resistance tests are obtained. This regimen consisted of of isoniazid, rifampicin, pyrazynamide, etambutol, fluoroquinolone and kanamycin or amikacin; it was well-tolerated and did not increase a rate of antibacterial resistance of Mycobacterium tuberculosis.

Conclusion. Given primary (5-10\%) and secondary (15-30\%) multi-drug resistance of Mycobacterium tuberculosis in Russian Federation, the most effective chemotherapeutic regimen for patients with pulmonary tuberculosis is the combination of isoniazid, rifampicin, pyrazynamide, etambutol, fluoroquinolone and kanamycin or amikacin. A proven microbiological method for individual control of drug sensitivity of M.tuberculosis and response to chemotherapy is culturing of sputum or another biomaterial on solid or liquid media using the BACTEC MGIT equipment. Key words: pulmonary tuberculosis, evidence-based medicine, multi-drug resistance, chemotherapy.

\section{Резюме}

По результатам метаанализа и систематического обзора литературы показано, что в Российской Федерации при уровне первичной (5-10 \%) и вторичной (15-30\%) множественной лекарственной устойчивости микобактерий туберкулеза (МБТ) эффективным режимом химиотерапии (XТ) у больных туберкулезом легких (ТЛ) является комбинация препаратов, состоящая из изониазида, рифампицина, пиразинамида, этамбутола, фторхинолона и канамицина или амикацина. При этом доказанным и объективным микробиологическим методом в индивидуальном контроле над лекарственной чувствительностью МБТ и эффективностью ХТ у больных ТЛ является посев мокроты или другого биологического материала на твердые или жидкие питательнее среды с использованием автоматизированной системы BACTEC MGIT.

Ключевые слова: туберкулез легких, доказательная медицина, лекарственная устойчивость, химиотерапия туберкулеза.

В настоящее время в Российской Федерации (РФ) химиотерапия (ХT) больных туберкулезом легких (ТЛ) проводится в соответствии с Приказом Минздрава России № 109 от 21.03.03 и Национальным руководством по фтизиатрии (2007) [1, 2]. В период 2003-2012 гг. в эпидемиологии ТЛ произошли определенные изменения. Показатель заболеваемости снизился с 83,1 до 68,1 на 100 тыс. населения, а показатель смертности - с 21,8 до 12,5 . Однако за этот же период существенно повысился уровень первичной и вторичной множественной лекарственной устойчивости (МЛУ) микобактерий туберкулеза (МБТ).
Так, первичная МЛУ, определяющая ее региональную распространенность у впервые выявленных больных, увеличилась в 6 раз (с 3,1 до 19,5\%), при этом распространенность МЛУ по федеральным округам была различна и колебалась с $14 \%$ в Центральном до 24,4 \% в Северо-Западном округе. Вторичная МЛУ, свидетельствующая о неэффективности ХТ, увеличилась в 3 раза (с 16,2 до 48,2 \%). На этом фоне произошло снижение показателя клинического излечения больных ТЛ, что в значительной мере связано с неэффективностью применяемых режимов ХТ (РХТ) при высоком уровне первичной МЛУ [3-11]. 
Это в значительной степени связано с тем, что у 75,5\% впервые выявленных больных отмечены распространенные клинические формы ТЛ: инфильтративный, фиброзно-кавернозный ТЛ и казеозная пневмония. При этом число пациентов с кавернами в легких составляло 59,1\%, с МБТ - 64,1\%, с МЛУ - 17,3\%. Клиническое излечение у них не превышает $50 \%$, а в 15-25\% случаев формируется хронический и крайне эпидемиологически опасный фиброзно-кавернозный ТЛ [2, 5, 8-11].

Для лечения больных ТЛ в настоящее время используются противотуберкулезные препараты (ПТП), из которых стрептомицин $(\mathrm{S})$, изониазид $(\mathrm{H})$, пиразинамид $(\mathrm{Z})$, циклосерин (Cs), канамицин $(\mathrm{Km})$, амикацин $(\mathrm{Am})$, капреомицин $(\mathrm{Cm})$, протионамид (Pto) и парааминосалицилат натрия (Pas) применяются уже в течение 60-70 лет, а рифампицин (R) и этамбутол (E) - 40-50 лет [2, 4, 5, 12-14]. За столь длительный период этими ПТП лечились миллионы больных ТЛ, сменились $\geq 2-3$ поколений, что оказало влияние на генетические структуры человека с возможными мутациями в генах, контролирующих синтез ферментов, ответственных за метаболизм ксенобиотиков. При этом можно с уверенностью предположить, что в организме современных больных по-другому осуществляется метаболизм этих ПТП, снижается их активность в результате выработанных через поколения людей генетических защитных механизмов. Естественно, что комбинации из старых 3-4 ПТП уже является недостаточно эффективной и служит одним из ведущих факторов развития МЛУ МБТ [4, 5, 9, 11, 15-18]. Косвенно это подтверждается тем, что в 1950-60-х гг. при лечении изониазидом нежелательные эффекты диагностировались у 35-40 \% больных ТЛ при высоком его содержании в крови (> 80 г / мл ) и медленном ацетилировании в печени (в > $80 \%$ случаев), а в 1-м 10 -летии XXI в. нежелательные эффекты выявлялись всего у 5-10 \% пациентов с медленным ацетилированием (в $<15 \%$ случаев) [2, 12, 13, 19, 20].

При идентификации этих генетических структур у конкретного больного в недалеком будущем будут определяться персональная чувствительность организма больных ТЛ к ПТП и основанная на этом персонифицированная ХТ [14].

Относительно новыми и высокоэффективными ПТП являются противотуберкулезные фторхинолоны (Fq): ломефлоксацин, ципрофлоксацин, офлоксацин (Ofl), левофлоксацин (Lfl), моксифлоксацин (Mfl), которые применяются в течение 15-20 лет в России и за рубежом [21-26]. В то же время по данным Европейской обсерватории по системам и политике в здравоохранении, в обозримом будущем других новых ПТП не будет [27].

В отечественных публикациях последнего времени, посвященных клиническим рекомендациям по ХT, стали появляться противоречивые методики и оценки эффективности лечения у впервые выявленных больных ТЛ.

Противоречия в этих публикациях касаются 3 основных вопросов:
- повышение эффективности ХТ у впервые выявленных больных ТЛ с помощью имеющихся на настоящее время и старых ПТП;

- какие и сколько ПТП должны входить в РХТ у впервые выявленных больных при высоком уровне первичной МЛУ МБТ в России;

- необходимость проведения рандомизированных клинических исследований и использования принципов доказательной медицины для обоснования клинических и экономических индикаторов эффективности предлагаемых клинических рекомендаций по ХТ у впервые выявленных больных.

Ответы на эти вопросы имеют большое практическое значение, т. к. противоречивые публикации, в первую очередь, ставят в затруднительное положение фтизиатров, непосредственно занимающихся лечением больных ТЛ. Во многих публикациях эмпирического и в основном умозрительного характера отсутствует какая-либо доказательная база.

Целью настоящего метаанализа и систематического обзора литературы явилась оценка всех опубликованных работ по рандомизированным и клиническим исследованиям для обоснования наиболее доказанных и эффективных клинических рекомендаций по ХТ у впервые выявленных больных ТЛ при высоком уровне первичной и вторичной МЛУ МБТ в РФ. При этом использовались общепринятые принципы доказательной медицины [28-32].

При проведении в 1998-2003 гг. комплексных экспериментальных, микробиологических и клинических исследований, касающихся высокой эффективности фторхинолонов у впервые выявленных больных ТЛ отечественными фтизиатрами впервые создан и доказательно обоснован новый высокоэффективный PXT, состоящий из комбинации $\operatorname{HRZEKm}(\mathrm{Am}) \mathrm{Fq}$ для России [4, 5, 17, 19, 20, 33]. Согласно Приказу Минздрава России № 109 от 21.03.03 данный режим получил название ІІБ РХТ [1] и был рекомендован для лечения больных с впервые выявленным ТЛ в регионах с высоким (> $5 \%$ ) уровнем распространения МЛУ МБТ в интенсивную фазу ХТ - до получения результатов исследования лекарственной чувствительности МБТ при посеве мокроты или другого биологического материала на твердые питательные или жидкие среды - с использованием автоматизированной системы ВАСТЕС MGIT в противоположность I PXT (HRZE) [2].

C помощью предлагаемого набора ПТП при ІІБ PХT обеспечивается комплексный бактерицидный эффект, т. к. при использовании HRE подавляется размножение чувствительных к ним МБТ, пиразинамида - оказывается воздействие на МБТ, находящиеся в участках казеоза, а $\mathrm{KmFq}$ - обеспечивается эффект при наличии лекарственной устойчивости (ЛУ) к изониазиду и / или рифампицину. При полирезистентности и МЛУ бактерицидный эффект обеспечивается также ZEKm(Am)Fq, при этом тормозится усиление устойчивости к другим ПТП. В то же время при использовании комбинации ПТП во ІІБ РХТ оказывается не только суммарный антибактериаль- 
ный, но и качественно новый синергичный бактерицидный эффект взаимодействия HRZEKm(Am)Fq [2, 5, 17, 21-26, 30, 33].

В РФ впервые было проведено многоцентровое рандомизированное клиническое исследование сравнительного изучения эффективности ІІБ и I PXT у впервые выявленных больных деструктивным ТЛ, в котором принимали участие специалисты ЦНИИ туберкулеза (ЦНИИТ) РАМН, Санкт-Петербургского НИИ фтизиопульмонологии, Новосибирского НИИ туберкулеза, противотуберкулезных учреждений Федеральной службы исполнения наказаний (ФСИН) России и кафедры фтизиопульмонологии МГМСУ им. А.И.Евдокимова. Во ІІБ РХТ использовался комбинированный ПТП Ломекомб (HZELomfl) [2, 24] в сочетании с раздельным приемом рифампицина и канамицина (амикацина) [35-45].

В данном исследовании доказано, что при первичной МЛУ МБТ, выявленной у 22,4 \% больных, через 3 мес. интенсивной фазы лечения ІІБ РХТ прекращение бактериовыделения установлено в 96,7 \% случаев, закрытие каверн в легких - у 74,2 \% пациентов, а у получавших I PXT, - в 63,3 и 32,5 \% случаев соответственно $(p<0,05)$. При использовании ІІБ РХТ полирезистентность преодолевается в $100 \%$ случаев, а МЛУ - в 52,9 \%, при I РХТ - в 29 и 6,3 \% случаев соответственно $(p<0,05)$. При проведении ІІБ РХТ не вызвано усиления ЛУ к ПТП ни у одного больного, а при I РXT - таковая отмечена у > 1/2 пациентов, в т. ч. и к резервным ПТП. Нежелательные реакции при лечении ІІБ РХТ встречались у 19,2 \% больных, а в случае I РXТ - в 22,5\% $(p<0,05)$, при этом все реакции были устранимыми.

Согласно результатам, полученным ФСИН России [46] и Санкт-Петербургским НИИ фтизиопульмонологии [47], изданы Методические рекомендации для фтизиатров по практическому применению ІІБ РХТ у впервые выявленных больных ТЛ и при рецидивах заболевания в регионах с высоким уровнем первичной МЛУ МБТ.

Аналогичные данные по высокой эффективности ІІБ РХТ при раздельном приеме изониазида, рифампицина, пиразинамида, этамбутола, офлоксацина, канамицина (амикацина) у больных с впервые выявленным деструктивным ТЛ были получены в ЦНИИТ РАМН [48, 49]: установлено, что при первичной МЛУ МБТ, выявленной у 24,9\% больных, через 3 мес. интенсивной фазы ХТ прекращение бактериовыделения отмечено при ІІБ РХТ в 94,1 \% случаев, а при I PXT - в 59,7 \% ( $p<0,05)$. Также при использовании ІІБ РХТ в $100 \%$ случаев преодолевалась монорезистентность, в 94,3\% - полирезстентность, в 80 \% случаев - МЛУ, в то время как использовании I PXТ только в 88,5, 61,9 и $20 \%$ случаев соответственно $(p<0,05)$. Закрытие каверн при ІІБ РХТ установлено у 29,8 \% пациентов, а при I РXТ - у 7,5 \% ( $p<0,001)$. Через 6 мес. лечения прекращение бактериовыделения и закрытие каверн было отмечено у $100 \%$ больных при ІІБ РXТ, а при I РXТ - у 85,1 и 56,9 \% пациентов соответственно. Наиболее важным доказанным фактом при использовании ІІБ РХТ явля- лось отсутствие усиления ЛУ к ПТП, а при I PXТ усиление отмечено в 14,9 \% случаев, в т. ч. и к резервным ПТП.

Частота побочных реакций при ІІБ и I РXТ существенно не различалась и составила 60,6 и 43,3\% соответственно $(p<0,05)$ за счет нарушений состава кишечной микрофлоры и удлинения интервала $Q-T$ на электрокардиограмме без клинических проявлений. Все реакции корригировались с помощью патогенетических методов лечения.

На основании данных рандомизированных клинических исследований сделан вывод, что добавление к 4 основным ПТП (HEZE) канамицина (амикацина) и фторхинолона при использовании ІІБ РХТ не влияет на частоту побочных реакций, однако при этом значительно повышается эффективность интенсивной фазы ХТ и создаются условия для качественного клинического излечения в процессе основного курса лечения.

Многоцентровое рандомизированное исследование сравнительной эффективности ІІБ и I PXT у впервые выявленных больных деструктивным ТЛ проведено в гражданских противотуберкулезных диспансерах Москвы, Московской, Смоленской, Кировской и Кемеровской областей, где уровень первичной МЛУ МБТ составлял 11,1-22,7 \%, и в пенитенциарных противотуберкулезных стационарах УФСИН Воронежской, Ивановской, Кировской и Нижегородской областей, где уровень первичной МЛУ 15,8-29 \% [23, 50-56].

Установлено, что при использовании ІІБ РХТ в интенсивной фазе лечения в течение 3 мес. прекрашение бактериовыделения по микроскопии мокроты отмечается у $100 \%$ больных, по посеву - у 89,2\%, при этом в $100 \%$ случаев удалось преодолеть монои полирезистентность и в 69,2\% - МЛУ, в т. ч. у больных в сочетании с ВИЧ-инфекцией [56]. При использовании I РХТ бактериовыделение прекратилось у 54,2 и 45,8 \% больных соответственно при этом моно- и полирезистентность удалось преодолеть в 69,2 и 17,4\% случаев соответственно, а МЛУ ни у одного больного $(p<0,01)$. Закрытие каверн при ІІБ РХТ отмечено в 71,7 \% случаев, клиническое излечение - в 94,2 \%, ранние рецидивы - в 2,6\%, а при I PXT - в 45,8; 65 и 20,5 \% случаев соответственно, при этом у $55 \%$ пациентов констатировано формирование фиброзно-кавернозного ТЛ с высоким уровнем усиления и формирования вторичной МЛУ $(p<0,01)$

По результатам рандомизированных и клинических исследований подтверждена высокая эффективность ІІБ РХТ у впервые выявленных больных ТЛ при высоком уровне МЛУ МБТ и абсолютная неэффективность I PXТ. Установлено, что среди противотуберкулезных фторхинолонов наиболее эффективным и оптимальным является левофлоксацин [23]. Благодаря данным исследованиям создан новый комбинированный ПТП Левофлорипин (HRZLfl) [57].

При экспериментальных микробиологических исследованиях в ЦНИИТ РАМН установлено, что левофлорипин эффективен в отношении МБТ лабора- 
торного штамма H37Rv и клинически чувствительных к ПТП штаммов высоким бактериостатическим и бактерицидным действием при низкой концентрации: минимальные ингибирующие концентрации (МИК) - 0,35, минимальные бактерицидные концентрации (МБК) - 0,52 мкг / мл, что в 2 раза ниже бактериостатической и бактерицидной концентрации изониазида $(0,72$ и 1,04 мкг / мл соответственно) $(p<0,01)$. Также установлено наличие синергизма взаимодействия ПТП, входящих в состав данного препарата, его высокая специфическая активность в отношении МБТ лабораторного штамма $\mathrm{H} 37 \mathrm{Rv}$ и клинически чувствительных к ПТП штаммов, а также бактерицидное действие в отношении МЛУ и широкой ЛУ штаммов МБТ при достаточно низких МИК и МБК (37,5; 187; 50,0 и 187 мкГ / мл соответственно) [26, 57].

В клиническом исследовании при применении ІІБ РХТ с Левофлорипином в сочетании с этамбутолом и канамицином (амикацином) у больных с впервые выявленным деструктивным ТЛ через 3 мес. лечения установлено прекращение выделения МБТ в 93,1 \% случаев, закрытие каверн в легких в 21,7 \%, а при применении I РХТ - в 60 и 5 \% слу- чаев соответственно $(p<0,01)$. Неустранимых побочных реакций не выявлено, все реакции корригировались применением патогенетических методов лечения [58-60].

В таблице представлен метаанализ научных публикаций в РФ по рандомизированным клиническим исследованиям сравнительной эффективности ХТ у впервые выявленных больных ТЛ по показателям прекращения бактериовыделения и закрытия каверн в легких при использовании ІІБ и I РXТ у впервые выявленных больных деструктивным ТБ при различных уровнях первичной МЛУ МБТ. При уровне первичной МЛУ МБТ в пределах 9,8-33,4 \% применение в интенсивной фазе лечения ІІБ РXТ (HRZEKm / AmFq) у впервые выявленных больных деструктивным ТЛ ( $n=1$ 646) позволило добиться прекращения бактериовыделения в 1495 (90,8\%) случаев, закрытия каверн в легких - в 990 (60,1\%), а применение I PXT ( $n=1614)$ - у 855 (53\%) и 412 $(25,5 \%)$ пациентов соответственно $(p<0,01)$ (см. таблицу). В то же время при лечении ІІБ РХТ ни у одного из 151 (9,2 \%) больного после завершения интенсивной фазы лечения не было установлено усиления ЛУ к применяемым ПТП, тогда как у 759

таблица

Метаанализ сравнительной эффективности ІІБ и І РХТ через 3 мес. интенсивной фазы лечения по показателям прекращения выделения МБТ и закрытия каверн в легких у впервые выявленных больных деструктивным ТЛ при различном уровне первичной МЛУ МБТ

\begin{tabular}{|c|c|c|c|c|c|c|c|c|c|c|}
\hline \multirow{3}{*}{$\begin{array}{l}\text { Источ- } \\
\text { ник }\end{array}$} & \multirow{3}{*}{$\begin{array}{l}\text { Год пуб- } \\
\text { ликации }\end{array}$} & \multirow{3}{*}{$\begin{array}{c}\text { Первичная } \\
\text { млу, \% }\end{array}$} & \multirow{3}{*}{$\begin{array}{l}\text { Число } \\
\text { больных }\end{array}$} & \multicolumn{6}{|c|}{ Эффективность интенсивной фазы лечения } & \multirow[t]{3}{*}{$p$} \\
\hline & & & & \multicolumn{3}{|c|}{ IIБ PXT, $n(\% \pm m)$} & \multicolumn{3}{|c|}{ I PXT, $n(\% \pm m)$} & \\
\hline & & & & $\begin{array}{c}\text { Число } \\
\text { больных }\end{array}$ & МБТ(-) & CV(-) & $\begin{array}{c}\text { Число } \\
\text { больных }\end{array}$ & МБТ(-) & CV(-) & \\
\hline [34] & 2007 & 30,6 & 59 & 39 & $39(100,0)$ & $19(48,7 \pm 8,0)$ & 20 & $12(60,0 \pm 9,9)$ & $5(25,0 \pm 9,6)$ & $<0,05$ \\
\hline [39] & 2007 & 9,8 & 60 & 30 & $28(93,3 \pm 4,5)$ & $16(53,3 \pm 9,1)$ & 30 & $19(63,3 \pm 8,8)$ & $4(13,3 \pm 6,1)$ & $<0,05$ \\
\hline [55] & 2007 & 16,7 & 120 & 60 & $60(100,0)$ & $32(53,3 \pm 6,4)$ & 60 & $37(61,7 \pm 6,2)$ & $25(41,7 \pm 6,3)$ & $<0,01$ \\
\hline [32] & 2008 & 13,6 & 500 & 250 & $172(68,8 \pm 2,9)$ & $55(10,0 \pm 1,9)$ & 250 & $59(23,6 \pm 2,7)$ & $3(1,2 \pm 0,7)$ & $<0,01$ \\
\hline [35] & 2008 & 23,3 & 60 & 30 & $29(96,7 \pm 3,2)$ & $16(53,3 \pm 9,1)$ & 30 & $17(56,6 \pm 9,0)$ & $12(40,0 \pm 8,9)$ & $<0,05$ \\
\hline [36] & 2008 & 13,3 & 120 & 60 & $56(93,3 \pm 3,2)$ & $37(61,7 \pm 6,3)$ & 60 & $35(58,3 \pm 6,3)$ & $20(33,3 \pm 6,1)$ & $<0,01$ \\
\hline [40] & 2008 & 11,7 & 60 & 30 & $30(100,0)$ & $27(90,0 \pm 5,4)$ & 30 & $20(66,7 \pm 8,6)$ & $8(26,7 \pm 8,0)$ & $<0,05$ \\
\hline [41] & 2008 & 35,0 & 60 & 30 & $23(76,7 \pm 7,7)$ & $17(56,7 \pm 9,0)$ & 30 & $10(33,3 \pm 8,6)$ & $3(10,0 \pm 5,4)$ & $<0,05$ \\
\hline [44] & 2008 & 24,9 & 161 & 94 & $88(93,6 \pm 6,3)$ & $56(59,6 \pm 5,1)$ & 67 & $42(62,7 \pm 5,9)$ & $5(7,5 \pm 3,2)$ & $<0,01$ \\
\hline [37] & 2008 & 21,4 & 60 & 30 & $27(90,0 \pm 5,4)$ & $18(60,0 \pm 8,9)$ & 30 & $18(60,0 \pm 8,9$ & $12(40,0 \pm 8,9)$ & $<0,05$ \\
\hline [33] & 2009 & 21,7 & 120 & 60 & $56(93,3 \pm 3,2)$ & $34(56,7 \pm 6,3)$ & 60 & $38(63,3 \pm 6,2)$ & $22(36,7 \pm 6,2)$ & $<0,01$ \\
\hline [38] & 2009 & 22,4 & 360 & 180 & $174(96,7 \pm 1,3)$ & $134(74,4 \pm 3,2)$ & 180 & $115(63,8 \pm 3,6)$ & $58(32,2 \pm 3,4)$ & $<0,01$ \\
\hline [21] & 2009 & 13,4 & 300 & 150 & $140(93,3 \pm 2,0)$ & $110(73,3 \pm 3,6)$ & 150 & $79(52,7 \pm 4,0)$ & $39(26,0 \pm 3,5)$ & $<0,01$ \\
\hline [46] & 2010 & 24,4 & 240 & 120 & $116(96,7 \pm 1,6)$ & $83(69,1 \pm 4,2)$ & 120 & $76(63,3 \pm 4,4)$ & $41(34,2 \pm 4,3)$ & $<0,01$ \\
\hline [45] & 2011 & 33,4 & 120 & 60 & $60(100,0)$ & $42(70,0 \pm 5,9)$ & 60 & $34(56,7 \pm 6,3)$ & $22(36,7 \pm 6,2)$ & $<0,01$ \\
\hline [47] & 2011 & 22,5 & 120 & 60 & $60(100,0)$ & $49(81,7 \pm 5,0)$ & 60 & $36(60,0 \pm 6,3)$ & $25(41,7 \pm 6,3)$ & $<0,01$ \\
\hline [49] & 2011 & 13,8 & 120 & 60 & $58(96,7 \pm 2,3)$ & $26(43,3 \pm 6,3)$ & 60 & $39(65,0 \pm 6,1)$ & $12(20,0 \pm 5,2)$ & $<0,01$ \\
\hline [48] & 2012 & 27,9 & 240 & 120 & $120(100,0)$ & $86(71,7 \pm 4,1)$ & 120 & $65(54,2 \pm 4,5)$ & $43(35,8 \pm 4,3)$ & $<0,01$ \\
\hline [54] & 2012 & 15,0 & 80 & 33 & $30(90,9 \pm 5,0)$ & $29(87,8 \pm 5,7)$ & 47 & $23(48,9 \pm 7,2)$ & $10(21,3 \pm 4,3)$ & $<0,01$ \\
\hline [51] & 2013 & 33,3 & 240 & 120 & $99(82,5 \pm 3,5)$ & $84(70,0 \pm 4,2)$ & 120 & $52(43,3 \pm 4,5)$ & $40(33,3 \pm 4,3)$ & $<0,01$ \\
\hline [50] & 2013 & 12,5 & 60 & 30 & $30(100,0)$ & $20(66,7 \pm 8,6)$ & 30 & $29(63,6 \pm 8,7)$ & $3(10,0 \pm 5,5)$ & $<0,01$ \\
\hline Bcero: & & & 3260 & 1646 & $1495(90,8 \pm 0,7)$ & $990(60,1 \pm 1,2)$ & 1614 & $855(53,0 \pm 1,2)$ & $412(25,5 \pm 1,1)$ & $<0,001$ \\
\hline
\end{tabular}

Примечание: МБТ(-) - прекращение бактериовыделения; CV(-) - закрытие каверн в легких; * - между IIБ и I PXT. 
(47 \%) пациентов с продолжающимся бактериовыделением, получавших I РXТ, по завершении интенсивной фазы лечения установлено усиление ЛУ не только к основным, но и к ряду резервных ПТП (капреомицин, канамицин, капреомицин и циклосерин).

Следовательно, при высоком уровне первичной МЛУ МБТ (10-30 \%) начальный РХТ (до получения микробиологических данных лекарственной чувствительности МБТ) должен включать основные ПТП (HRZE) в сочетании с канамицином (амикацином) и фторхинолонами, которые нерационально держать в резерве. Однако по данным ФГБУ "Центральный научно-исследовательский институт организации и информатизации здравоохранения" Минздрава России (2007-2012) I РXТ применяется у 71,5-73,1\% впервые выявленных больных ТЛ, а ІІБ РХТ - только у 8,1-12 \% [6-8]. При такой ХТ через 12 мес. лечения клиническое излечение достигается только у 48,8 \% больных деструктивным ТЛ с выделением МБТ [10].

Установлено, что применение ІІБ РХТ в интенсивной фазе лечения позволяет добиться клинического излечения в 94,2 \% случаев, а при ранних рецидивах - в 2,6\%, а I PXT - в 65 и в 20,5\% соответственно, при этом у $55 \%$ больных констатировано формирование фиброзно-кавернозного ТЛ с высоким уровнем вторичной МЛУ. При этом требуются дорогостоящие резервные ПТП и высокотехнологичные оперативные вмешательства [53].

Таким образом, при сравнительном анализе публикаций результатов исследований, проведенных среди впервые выявленных больных ТЛ ( $n=3260)$, получавших в интенсивную фазу лечения ІІБ и I PXT, доказано, что в современных эпидемиологических условиях в РФ при уровне первичной МЛУ 14,4 \% альтернативы ІІБ РХТ нет, т. к. в таком случае в 1,5 раза чаще прекращается бактериовыделение и в 2 раза чаще происходит закрытие каверн в легких. При продолжении использования у данного контингента пациентов I PXT в ближайшее время будут формироваться хронические неизлечимые формы с высоким уровнем МЛУ и широкой ЛУ МБТ.

Однако в 2012 г. появилось всего 2 публикации, полностью противоречащие многочисленным доказательным публикациям, представленным в систематическом обзоре литературы (см. таблицу).

В работе [61] приводятся данные ретроспективного когортного исследования отдаленных результатов лечения больных ТЛ $(n=1658)$, зарегистрированных в 2007-2008 гг. для лечения по I, IІА и ІІБ РХТ из 3 субъектов РФ. Установлено, что при МЛУ МБТ у 12,5 \% больных благоприятный положительный результат при применении I и IIA PXТ составил $89 \%$, а при использовании ІІБ РХТ - 73,3\%. При этом нарастание (усиление) спектра ЛУ при I PXТ составляет 24,6 \%, при IIA - 19,2 \%, а при ІІБ $45,6 \%(p<0,05)$.

А.Г.Самойловой и соавт. приводятся данные по 5 субъектам РФ о больных ТЛ ( $n=3187)$, зарегистрированных 2007-2008 гг. и получавших лечение по
I, IIA и ІІБ РХТ. Установлено, что при МЛУ МБТ у 19,4 \%, больных благоприятный положительный результат при применении I и IIA составил 87 \%, а при использовании ІІБ РХТ - 69,3\%. При этом нарастание (усиление) спектра ЛУ при I и IIA РХТ составляет 23,6 \%, а при ІІБ - 45,6\% $(p<0,05)$ [62].

Таким образом, в работах $[61,62]$ публикуются данные о полной неэффективности 6 ПТП: противотуберкулезных фторхинолонов (офлоксацин, левофлоксацин и моксифлоксацин) и аминогликозидов (канамицин и амикацин) при их сочетании с HRZE во ІІБ РХТ, но высокой эффективности 4 ПТП (HRZE) при лечении впервые выявленных больных ТЛ.

Это полностью противоречит опубликованным материалам И.А.Васильевой и соавт., где установлено, что через 3 мес. лечения ІІБ РХТ впервые выявленных больных деструктивным ТЛ прекращение бактериовыделения отмечено в $94,4 \%$ случаев, через 6 мес. - в $100 \%$, а через 3 мес. лечения I PXT - в 59,7 и $85,1 \%$ случаев соответственно $(p<0,05)$. При этом нарастание (усиление) ЛУ выявлено только при лечении I РXТ. При этом подчеркивается именно высокая эффективность противотуберкулезных фторхинолонов и канамицина (амикацина) при использовании ІІБ РXТ [48, 49].

В микробиологических исследованиях, проведенных НИИ фтизиопульмонологии Первого МГМУ им. И.М.Сеченова, Санкт-Петербургским НИИ фтизиопульмонологии и ЦНИИТ РАМН, а также за рубежом, получены доказательные данные о высокой бактерицидной активности противотуберкулезных фторхинолонов, МБТ-чувствительных как ко всем ПТП, так и с МЛУ и широкой ЛУ МБТ. Это является полным игнорированием многочисленных научных исследований ведущих отечественных специалистов по ХТ ТЛ, по результатам которых обосновано и доказано применение эффективных комбинаций ПТП и современных РХТ в России [2, 19, 23, 24, 32, 34-47, 50-60].

Данные, приведенные в работе И.А.Васильевой и соавт. "Методические материалы к проведению тематического цикла усовершенствования врачей. Диагностика и лечение ТЛ с МЛУ возбудителя", peкомендованные и откровенно навязываемые РФ Американским международным союзом здравоохранения и Агентством США по международному развитию совместно с ЦНИИТ РАМН и Российским обществом фтизиатров, также полностью противоречат публикациям отечественных фтизиатров [63]. В то же время это издание полностью дублирует Рекомендации по лечению туберкулеза Всемирной организации здравоохранения для слаборазвитых стран Африки, Азии и Южной Америки, имеющих уровень первичной МЛУ МБТ, не превышающий $3 \%$ [18, 31]. В России при уровне первичной МЛУ $19,5 \%$ эти рекомендации ни когда не апробировались, публикации по рандомизированным клиническим исследованиям отсутствуют.

Особые сомнения вызывают рекомендации по длительному применению (20-24 мес.) в РХТ боль- 
ных ТЛ с МЛУ и широкой ЛУ МБТ неспецифических антимикробных препаратов (амоксициллин / клавунат, кларитромицин и имипенем / циластин), которые отнесены в группу ПТП, но характер их действия на МБТ не выяснен [31, 63].

В то же время в микробиологических и молекулярно-генетических исследованиях приводятся данные о том, что МБТ имеют природную ("дикую") ЛУ к пенициллинам, b-лактамам, цефалоспоринам, ампициллинам, макролидам и карбапенемам [64]. Следует отметить, что в РФ эти антимикробные препараты используются с диагностической целью, как диагноз ex juvantibus в алгоритме дифференциальной диагностики ТЛ и внебольничной пневмонии. [65]. Учитывая эти никем не опровергнутые данные, а также отсутствие каких-либо публикаций, расценивать эти группы антимикробных препаратов как ПТП не имеет никакого научного и практического смысла.

Еще одно противоречие касается ориентации на молекулярно-генетические исследования в определении МЛУ МБТ у больных ТЛ, в частности применяемой в РФ тест-системы "ТБ-Биочип-1" и -2 для точного определения типа мутации, приводящей к ЛУ возбудителя ТЛ к 3 ПТП: рифампицину (ген rpoB), изониазиду (ген katG) и офлоксацину (ген gyrA). С помощью тест-системы "ТБ-Биочип-1" у больных ТЛ обнаруживается $\geq 95 \%$-ная устойчивость МБТ к рифампицину, но $\leq 60 \%$-ная - к изониазиду. Применение тест-системы "ТБ-Биочип-2" не позволяет достоверно обнаружить офлоксацинустойчивые МБТ, т. к. ЛУ к фторхинолонам кодируется 2 генами - gyrA и gyrB, который не определяется [66].

Р.Б.Дауровым, И.А.Васильевой и соавт. в ЦНИИТ РАМН при использовании тест-системы "ТБ-Биочип-1" на основании выявления ЛУ МБТ у впервые выявленных больных ТЛ к рифампицину и / или изониазиду и назначении IV PXT (CmCsPtoPasFq) через 2 мес. лечения установлено прекращение выделения МБТ в 54,3 \% случаев, а побочные реакции отмечены у $85 \%$ пациентов. Это требовало частого изменения режима лечения, отмены препаратов, длительных перерывов, индивидуального подбора отдельных препаратов, что определило неадекватность и неэффективность ХТ [67]. Однако Э.В.Ваниевым и соавт., И.А.Васильевой и соавт. и В.Ю.Мишиным показано, что у впервые выявленных больных ТЛ при применении ІІБ РХТ прекратилось выделение МБТ за этот же срок в 67,2 \% случаев, а побочные реакции отмечены только у $5 \%$ пациентов $(p>0,05)[48,49,68]$.

Следовательно, ориентация на тест-систему "ТББиочип-1" и -2, с помощью которой МЛУ достоверно не выявляется, ни с научной, ни с практической стороны не обоснована.

Таким образом, при проведении метаанализа и систематического обзора литературы установлено, что в РФ при уровне первичной МЛУ 5-10\% и вторичной - 15-30 \% единственным доказанным у впервые выявленных больных ТЛ является рекомендованный Приказом Минздрава России № 109 от 23.03.03 ІІБ РХТ, состоящий из HRZEFqKm(Am), которому в настоящее время альтернативы нет. При этом в настоящее время доказанными и объективными микробиологическими методами в индивидуальном контроле лекарственной чувствительности МБТ и эффективности ХТ у больных ТЛ является посев мокроты или другого биологического материала на твердые или жидкие питательные среды с использованием автоматизированной системы BACTEC MGIT. Молекулярно-генетические исследования в настоящее время еще не являются полностью соответствующими для определения точного типа мутации ко всем ПТП, применяемым для индивидуального лечения больных ТЛ.

Следует также отметить, что в штате противотуберкулезных диспансеров в РФ практически отсутствуют специалисты - молекулярные генетики.

\section{Заключение}

По результатам метаанализа рандомизированных клинических исследований отечественных публикаций объективно доказано, что в случае современной эпидемиологической ситуации по ТЛ в России, а также при отсутствии новых ПТП и невозможности исследования ЛУ МБТ ко всем ПТП с помощью молекулярно-генетических методов единственным высокоэффективным и безопасным при лечении впервые выявленных больных ТЛ является ІІБ РХТ.

Научно обоснованные, методически разработанные российскими фтизиатрами $[5,33]$ и регламентированные Приказом Минздрава России № 109 от 21.03.03 и Национальным руководством по фтизиатрии (2007) Клинические рекомендации по лечению ІІБ РХТ [2] применяются всего у 8-12\% впервые выявленных больных [6-8].

В случае повсеместной практической реализации данных клинических рекомендаций ожидается существенное улучшение эпидемиологической ситуации по ТЛ в России, увеличение показателя клинического излечения ТЛ, уменьшение числа рецидивов заболевания и снижение уровня региональной первичной и вторичной МЛУ МБТ. Это позволит создать благоприятные условия по качественной реализации мероприятий, направленных на совершенствование стратегии Национальной безопасности РФ в сфере здравоохранения и здоровья по ТЛ (2010) до 2020 г.

\section{Литература / References}

1. Приказ Минздрава РФ № 109 от 21.03.03 "О совершенствовании противотуберкулезных мероприятий в Российской федерации". М.; 2003. / The order of Healthcare Ministry of Russian Federation N 109 of the $21^{\text {st }}$ of March, 2003, "On Improvement of Anti-tuberculosis Measures in Russian Federation". Moscow; 2003 (in Russian).

2. Перельман М.И., ред. Фтизиатрия: Национальное руководство. М.; 2007. / Perelman M.I., ed. Phthisiology: National Guidelines. [Ftiziatriya: Natsional'noe rukovodstvo]. Moscow; 2007 (in Russian).

3. Шилова М.В. Туберкулез в России в 2003 году. М.; 2004. / Shilova M.V. Tuberculosis in Russia in 2003. [Tuberkulez v Rossii v 2003 godu]. Moscow; 2004 (in Russian). 
4. Мишин В.Ю. Химиотерапия туберкулеза легких. Пульмонология. 2008; 3: 5-14. / Mishin V.Yu. Chemotherapy of pulmonary tuberculosis. Pul'monologiya. 2008; 3: 5-14 (in Russian).

5. Мишин В.Ю. Туберкулез легких с лекарственной устойчивостью возбудителя. М.: ГЭОТАР-Медиа; 2009. / Mishin V.Yu. Drug Resistant Pulmonary Tuberculosis. [Tuberkulez legkikh s lekarstvennoy ustoychivost'yu vozbuditelya]. Moscow: GEOTAR-Media; 2009 (in Russian).

6. Алексеева Г.С., Михайлова Ю.В., Сон М.М. и др. Отраслевые показатели противотуберкулезной работы в 2007-2008 гг:: Статистические материалы. Тверь; 2009. / Alekseeva G.S., Mikhaylova Yu.V., Son M.M. et al. Branch Parameters of Anti-tuberculosis activity in 20072008: Statistic Data. [Otraslevye pokazateli protivotuberkuleznoy raboty v 2007-2008 gg.: Statisticheskie materialy]. Tver'; 2009 (in Russian).

7. Сон И.М., Нечаева О.Б., Стерлигов С.А. и др. Отраслевые показатели противотуберкулезной работы в 20092010 гг:: Статистические материалы. М.; 2011. / Son I.M., Nechaeva O.B., Sterligov S.A. et al. Branch Parameters of Anti-tuberculosis Activity in 2007-2008: Statistic Data. [Otraslevye pokazateli protivotuberkuleznoy raboty v 2009_ 2010 gg.: Statisticheskie materialy]. Moscow; 2011 (in Russian).

8. Стерлигов С.А., Сон И.М., Нечаева О.Б. и др. Отраслевые показатели противотуберкулезной работы в 20112012 гг.: Статистические материалы. М.; 2013. / Sterligov S.A., Son I.M., Nechaeva O.B. et al. Branch Parameters of Anti-tuberculosis Activity in 2007-2008. Statistic data. [Otraslevye pokazateli protivotuberkuleznoy raboty v 20112012 gg.: Statisticheskie materialy]. Moscow; 2013 (in Russian).

9. Богородская Е.М., Чернов М.И., Стерлигов С.А., Смердин C.B. Модификация стандартных режимов химиотерапии у впервые выявленных больных туберкулезом: распространение, причины назначения, исходы. Туберкулез и болезни легких. 2012; 4: 9-18. / Bogorodskaya E.M., Chernov M.I., Sterligov S.A., Smerdin S.V. Modification of standard chemotherapeutic regimens in patients with newly diagnosed tuberculosis: prevalence, indications, outcomes. Tuberkulez i bolezni legkikh. 2012; 4: 9-18 (in Russian).

10. Шилова М.В. Туберкулез в России в 2011 году. М.; 2012. / Shilova M.V. Tuberculosis in Russia in 2011. [Tuberkulez v Rossii v 2011 godu]. Moscow; 2012 (in Russian).

11. Панин И. В. Современная характеристика лекарственной устойчивости МБТ и особенности бактериовыделения до и на фоне стандартного лечения у больных туберкулезом органов дыхания: Дисс. ... канд. мед. наук. M.; 2013. / Panin I.V. Current Characteristics of Drug Resistance of Mycobacterium Tuberculosis and its Culturing Before and After Standard Treatment of Pulmonary Tuberculosis: Diss. Moscow; 2013 (in Russian).

12. Рабухин A.E. Химиотерапия больных туберкулезом. М.; 1970. / Rabukhin A.E. Chemotherapy of Tuberculosis. [Khimioterapiya bol'nykh tuberkulezom]. Moscow; 1970 (in Russian).

13. Хоменко А.Г. Химиотерапия туберкулеза легких. М.; 1980. / Khomenko A.G. Chemotherapy of pulmonary tuberculosis. [Khimioterapiya tuberkuleza legkikh]. Moscow; 1980 (in Russian).

14. Перельман М.И., Богадельникова И.В. Стандарт и персональная медицина в диагностике и лечении больных. Туберкулез и болезни легких. 2013; 1: 3-9. / Perel'- man M.I., Bogadel'nikova I.V. Standards and personalized medicine. Tuberkulez i bolezni legkikh. 2013; 1: 3-9 (in Russian).

15. Химиотерапия больных туберкулезом легких. Методические рекомендации МЗ СССР от 12.08.83. М.; 1983. / Chemotherapy of Pulmonary Tuberculosis. Methodological Guidelines of Healthcare Ministry of USSR of 12.08.83. [Khimioterapiya bol'nykh tuberkulezom legkikh. Metodicheskie rekomendatsii MZ SSSR ot 12.08.83]. Moscow; 1983 (in Russian).

16. Treatment of Tuberculosis. Guidelines for National Programmers. WHO / TB. Geneva; 1993.

17. Мишин В.Ю., Чуканов В.И. Феномен индукции нарастающей поливалентной лекарственной резистентности микобактерий при стандартных курсах химиотерапии. В кн.: Сборник тезисов Х Национального конгресса по болезням органов дыхания. СПб; 2000: 293. / Mishin V.Yu., Chukanov V.I. A phenomenon of induction of increasing multi-drug resistance of Mycobacterium tuberculosis in standard chemotherapy. In: The X National Congress on Respiratory Diseases Proceedings. [Sbornik tezisov X Natsional'nogo kongressa po boleznyam organov dykhaniya]. St Petersburg; 2000: 293 (in Russian).

18. Caminero J.A. Туберкулез с множественной лекарственной устойчивостью: эпидемиология, факторы риска и выявление случаев. Туберкулез и легочные заболевания. 2011; 2 (1): 33-44. / Caminero J.A. Multi-drug resistant tuberculosis: epidemiology, risk factors and detection of cases. Tuberkulez i legochnye zabolevaniya. 2011; 2 (1): 33-44 (in Russian).

19. Чучалин А.Г., ред. Рациональная фармакотерапия заболеваний органов дыхания: Руководство для практикующих врачей. М.; 2013. / Chuchalin A.G., ed. Rational Pharmacotherapy of Respiratory Disease: Practical handbook. [Ratsional'naya farmakoterapiya zabolevaniy organov dykhaniya: Rukovodstvo dlya praktikuyushchikh vrachey]. Moscow; 2013 (in Russian).

20. Мишин В.Ю. Медикаментозные осложнения комбинированной химиотерапии туберкулеза легких. М.: Издательство "Медицинское информационное агентство"; 2007. / Mishin V.Yu. Drug-induced Complications of Chemotherapy of Pulmonary Tuberculosis. [Medikamentoznye oslozhneniya kombinirovannoy khimioterapii tuberkuleza legkikh]. Moscow: Izdatel'stvo "Meditsinskoe informatsionnoe agentstvo"; 2007 (in Russian).

21. Можокина Г.Н. Препараты фторхинолонового ряда в комплексной терапии туберкулеза (экспериментальное исследование): Дисс. ... канд. мед. наук. М.; 1998. / Mozhokina G.N. Fluoroquinolones for Treatment of Tuberculosis (an Experimental Study): Diss. Moscow; 1998 (in Russian).

22. Соколова Г.Б. Левофлоксацин (Таваник) в комплексной терапии туберкулеза. Информационное письмо для врачей-фтизиатров. M.; 2004. / Sokolova G.B. Levofloxacin (Tavanik) for Treatment of Tuberculosis: An Information Letter for Practical Phthisiatricians. [Levofloksatsin (Tavanik) v kompleksnoy terapii tuberkuleza. Informatsionnoe pis'mo dlya vrachey-ftiziatrov]. Moscow; 2004 (in Russian).

23. Мишин В.Ю. Эффективность различных препаратов группы фторхинолонов во ІІБ режиме химиотерапии при лечении впервые выявленных больных туберкулезом легких. В кн.: Сборник материалов XVI Российского национального конгресса "Человек и лекарство". M.; 2009: 184-185. / Mishin V.Yu. Efficacy of different fluoroquinolones in chemotherapeutic IIB regimen in newly 
diagnosed pulmonary tuberculosis. In: The XXI Russian National Congress "A Human and a Medicine" Proceedings. [Sbornik materialov XVI Rossiyskogo natsional'nogo kongressa "Chelovek i lekarstvo"]. Moscow; 2009: 184-185 (in Russian).

24. Соколова Г.Б. Клиническая и экспериментальная фармакология как основа стратегии и тактики химиотерапии туберкулеза (1970-2008 гг.). Туберкулез и болезни легких. 2009; 12: 32-37. / Sokolova G.B. Clinical and experimental pharmacology as a basis of anti-tuberculosis chemotherapeutic strategy. Tuberkulez i bolezni legkikh. 2009; 12: 32-37 (in Russian).

25. Борисов С.Е., Мохирева Л.В., Иванушкина Т.Н. и др. Фторхинолоны в лечении туберкулеза - в поисках новой парадигмы (обзор зарубежной литературы). Туберкулез и болезни легких. 2011; 12: 5-16. / Borisov S.E., Mokhireva L.V., Ivanushkina T.N. et al. Tuberculosis and pulmonary diseases (review). Tuberkulez i bolezni legkikh. 2011; 12: 5-16 (in Russian).

26. Мохирева Л.В., Мартынова Л.П., Черноусова Л.Н. и др. Микробиологическое изучение комплексного противотуберкулезного препарата Левофлорипина in vitro. Туберкулез и болезни легких. 2011; 10: 63-67. / Mokhireva L.V., Martynova L.P., Chernousova L.N. et al. Microbiological investigation of the combined anti-tuberculosis drug Levoflorilin. Tuberkulez i bolezni legkikh. 2011; 10: 63-67 (in Russian).

27. Кукер Р., Отум Р., МасКи М. Проблемы здравоохранения и инфекционных заболеваний: Пер. с англ. Европейская Обсерватория по системам и политике в здравоохранении. ВО3; 2009. / Kuker R., Otum R., MasKi M. Healthcare and Infection Diseases Problems. [Problemy zdravookhraneniya i infektsionnykh zabolevaniy]: Per. s angl. Evropeyskaya Observatoriya po sistemam i politike v zdravookhranenii. VOZ; 2009 (in Russian).

28. Мишин В.Ю., Кононец А.С. Эффективность химиотерапии и стойкость клинического излечения у впервые выявленных больных деструктивным туберкулезом легких с позиций доказательной медицины. Пульмонология. 2012; 5: 41-49. / Mishin V.Yu., Kononets A.S. Evidence-based efficacy of chemotherapy and stability of clinical recovery of newly diagnosed patients with cavitary pulmonary tuberculosis. Pul'monologiya. 2012; 5: 41-49 (in Russian).

29. Стародубов В.И., Ступакова И.Н., Самородская И.В. Доказательная медицина и менеджмент в здравоохранении. М.: МЦФЭР; 2005. / Starodubov V.I., Stupakova I.N., Samorodskaya I.V. Evidence-based Medicine and Healthcare Management. [Dokazatel'naya meditsina i menedzhment v zdravookhranenii]. Moscow: MTsFER; 2005 (in Russian).

30. Мишин В.Ю. Лечение впервые выявленных больных туберкулезом легких на основе принципов доказательной медицины. Consilium Medicum. 2008; 10 (3): 20-25. / Mishin V.Yu. Evidence-based treatment of newly diagnosed patients with cavitary pulmonary tuberculosis. Consilium Medicum. 2008; 10 (3): 20-25 (in Russian).

31. Treatment of Tuberculosis Guidelines. 4th ed. Geneva: WHO / HTM; 2009.

32. Хенеган К., Баденоч Д. Доказательная медицина: Пер. с англ. М.; 2011. / Khenegan K., Badenoch D. Evidencebased Medicine. [Dokazatel'naya meditsina]: Per. s angl. Moscow; 2011 (in Russian).

33. Мишин В.Ю., Борисов С.Е., Соколова Г.Б. и др. Разработка современных протоколов диагностики и лечения туберкулеза органов дыхания. Consilium Medicum. 2001; 3 (3): 148-154. / Mishin V.Yu., Borisov S.E., Sokolova G.B. et al. Development of modern protocols for diagnosis and treatment of pulmonary tuberculosis. Consilium Medicum. 2001; 3 (3): 148-154 (in Russian).

34. Ерохин В.В., Мишин В.Ю., Чуканов В.И. и др. Казеозная пневмония. М.: Медицина; 2008. / Erokhin V.V., Mishin V.Yu., Chukanov V.I. et al. Caseous Pneumonia [Kazeoznaya pnevmoniya]. Moscow: Meditsina; 2008 (in Russian).

35. Кононеи А.С. Эффективность лечения лекарственно-устойчивого туберкулеза легких в исправительных учреждениях ФСИН России: Дисс. ... Д-ра мед. наук. M.; 2009. / Kononets A.S. Efficacy of treatment of Drugresistant Pulmonary Tuberculosis in Penitentiary Settings of Russia. [Effektivnost' lecheniya lekarstvenno-ustoychivogo tuberkuleza legkikh $\mathrm{v}$ ispravitelnykh uchrezhdeniyakh FSIN Rossii]: Diss. Moscow; 2009 (in Russian).

36. Келасова Н.В., Аксенова В.А. Эффективность лечения препаратом "Ломекомб" молодых больных туберкулезом легких. Врач. 2007; 8: 32-33. / Kelasova N.V., Aksenova V.A. Efficacy of the combined drug "Lomecomb" in young patients with pulmonary tuberculosis. Vrach. 2007; 8: 32-33 (in Russian).

37. Кононеи А.С., Мишин В.Ю. Эффективность лечения впервые выявленных больных туберкулезом легких с высоким уровнем развития лекарственной устойчивости возбудителя. Инфекционные болезни. 2008; 6 (4): 68-71. / Kononets A.S., Mishin V.Yu. Therapeutic efficacy in newly diagnosed pulmonary tuberculosis having a high probability of drug resistance development. Infektsionnye bolezni. 2008; 6 (4): 68-71 (in Russian).

38. Краснов В.А., Свистельник А.В., Степанов Д.В. и др. Эффективность и безопасность комбинированного противотуберкулезного препарата Ломекомб при лечении впервые выявленных больных деструктивным туберкулезом легких с бактериовыделением и высоким риском развития лекарственной устойчивости микобактерий туберкулеза. В кн.: Сборник тезисов XV Российского национального конгресса "Человек и лекарство". М.; 2008. 181-182. / Krasnov V.A., Svistel'nik A.V., Stepanov D.V.et al. Efficacy and safety of the combined antituberculosis drug Lomecomb in newly diagnosed smear-positive cavitary pulmonary tuberculosis patients with high risk of drug resistance development. In: The XV Russian National Congress "A Human and a Medicine" Proceedings. [Sbornik tezisov XV Rossiyskogo natsional'nogo kongressa "Chelovek i lekarstvo"]. Moscow; 2008. 181-182 (in Russian).

39. Левашов Ю.Н., Елькин А.В., Скворцова Л.А. и др. Оценка эффективности и безопасности комбинированного противотуберкулезного препарата Ломекомб при лечении впервые выявленных больных деструктивным туберкулезом легких. В кн.: Сборник тезисов XV Российского национального конгресса "Человек и лекарство". М.; 2008. 196. / Levashov Yu.N., El'kin A.V., Skvortsova L.A. et al. Evaluation of efficacy and safety of the combined antituberculosis drug Lomecomb in patients with newly diagnosed cavitary pulmonary tuberculosis. In: The XV Russian National Congress "A Human and a Medicine" Proceedings. [Sbornik tezisov XV Rossiyskogo natsional'nogo kongressa "Chelovek i lekarstvo"]. Moscow; 2008: 196 (in Russian).

40. Левашов Ю.Н., Мишин В.Ю., Краснов В.А. и др. Многоцентровые исследования эффективности ІІБ режима химиотерапии с использованием комбинированного 
препарата Ломекомб при лечении впервые выявленных больных туберкулезом легких с бактериовыделением. В кн.: Сборник тезисов XV Российского национального конгресса "Человек и лекарство". М.; 2009: 157. / Levashov Yu.N., Mishin V.Yu., Krasnov V.A. et al. Multicenter investigations of efficacy IIB chemotherapeutic regimen using the combined antituberculosis drug Lomecomb in patients with newly diagnosed smear-positive pulmonary tuberculosis. In: The XV Russian National Congress "A Human and a Medicine" Proceedings. [Sbornik tezisov XV Rossiyskogo natsional'nogo kongressa "Chelovek i lekarstvo"]. Moscow; 2009: 157 (in Russian).

41. Мишин В.Ю., Комиссарова О.Г., Кононеи А.С. и др. Эффективность применения комбинированного противотуберкулезного препарата Ломекомб при лечении впервые выявленных больных деструктивным туберкулезом легких. В кн.: Материалы VIII Российского съезда фтизиатров: "Туберкулез в России". М.; 2007: 440-441. / Mishin V.Yu., Komissarova O.G., Kononets A.S. et al. Efficacy of the combined antituberculosis drug Lomecomb in patients with newly diagnosed cavitary pulmonary tuberculosis. In: Materials of the VIII Russian Phthisiatric Congress "Tuberculosis in Russia". [Materialy VIII Rossiyskogo s"ezda ftiziatrov: "Tuberkulez v Rossii"]. Moscow; 2007: 440-441 (in Russian).

42. Мишин В.Ю., Комисарова О.Г., Багдасарян Т.Р. и др. Эффективность комбинированного противотуберкулезного препарата Ломекомб при лечении впервые выявленных больных туберкулезом легких. В кн.: Сборник тезисов XV Российского национального конгресса "Человек и лекарство". М.; 2008. 230. / Mishin V.Yu., Komisarova O.G., Bagdasaryan T.R. et al. Efficacy of the combined antituberculosis drug Lomecomb in patients with newly diagnosed pulmonary tuberculosis. In: The XV Russian National Congress "A Human and a Medicine" Proceedings. [Sbornik tezisov XV Rossiyskogo natsional'nogo kongressa "Chelovek i lekarstvo"]. Moscow; 2008. 230 (in Russian).

43. Смердин А.В., Чернов М.Т., Иванова О.В. и др. Эффективность комбинированного противотуберкулезного препарата Ломекомб при химиотерапии впервые выявленных больных деструктивным туберкулезом легких с бактериовыделением. В кн.: Сборник тезисов XV Pоссийского национального конгресса "Человек и лекарство". М.; 2008: 305. / Smerdin A.V., Chernov M.T., Ivanova $O . V$. et al. Efficacy of the combined antituberculosis drug Lomecomb in patients with newly diagnosed cavitary smear-positive pulmonary tuberculosis. In: The XV Russian National Congress "A Human and a Medicine" Proceedings. [Sbornik tezisov XV Rossiyskogo natsional'nogo kongressa "Chelovek i lekarstvo"]. Moscow; 2008: 305 (in Russian).

44. Mishin V.J., Levashov J.N., Elkin A.V. et al. Efficincy of Russian combined antituberculosis drag Lomecomb in treatment for new-onset pulmonary tuberculosis. In: Abstract book of 39th World Conference on Lang Health of the International Union Against Tuberculosis and Lung Disease (The Union). Paris; 2008: 319.

45. Mishin V., Levashov J., Elkin A. et al. Multicenter randomized clinic study of new standard chemotherapy regiment for new cases patients of pulmonary tuberculosis executed in Russia regions with high level of multiple drug resistance (MDR). Eur. Respir. J. 2009; 34 (Suppl. 53): 2618.

46. Кононеи А.С., Мишин В.Ю., Сидорова С.В. Методические рекомендации по химиотерапии впервые выявлен- ных больных туберкулезом легких и больных рецидивами деструктивного туберкулеза с бактериовыделением в учреждениях уголовно-исполнительной системы Российской Федерации. М.; 2006. / Kononets A.S., Mishin V.Yu., Sidorova S.V. Methodological Guidelines on Chemotherapy of Patients with Newly Diagnosed Pulmonary Tuberculosis and Patients with Recurrent Cavitary Smear-positive Tuberculosis in Penitentiary Settings. [Metodicheskie rekomendatsii po khimioterapii vpervye vyyavlennykh bol'nykh tuberkulezom legkikh i bol'nykh retsidivami destruktivnogo tuberkuleza s bakteriovydeleniem v uchrezhdeniyakh ugolovno-ispolnitel'noy sistemy Rossiyskoy Federatsii]. Moscow; 2006 (in Russian).

47. Левашов Ю.Н., Елькин А.В., Павлова М.Н. и др. Методические рекомендации по химиотерапии больных деструктивным туберкулезом легких с бактериовыделением (впервые выявленных и с рецидивами) Санкт-Петербургского НИИ фтизиопульмонологии Росмедтехнологий. М.; 2008. / Levashov Yu.N., El'kin A.V., Pavlova M.N. et al. Methodological Guidelines on Chemotherapy of Patients with Newly Diagnosed and Recurrent Cavitary Smear-positive Pulmonary Tuberculosis. [Metodicheskie rekomendatsii po khimioterapii bol'nykh destruktivnym tuberkulezom legkikh s bakteriovydeleniem (vpervye vyyavlennykh i s retsidivami) Sankt-Peterburgskogo NII ftiziopul'monologii Rosmedtekhnologiy]. Moscow; 2008 (in Russian).

48. Ваниев Э.В., Васильева И.А., Абдулаев Р.Ю. и др. Использование фторхинолонов в интенсивной фазе лечения впервые выявленных больных деструктивным туберкулезом легких. Проблемы тубуберкулеза и болезни легких. 2008; 10: 57-60. / Vaniev E.V., Vasil'eva I.A., Abdulaev R.Yu. et al. Intensive treatment of patients with newly diagnosed cavitary pulmonary tuberculosis with fluoroquinolones. Problemy tububerkuleza i bolezni legkikh. 2008; 10: 57-60 (in Russian).

49. Vasilyeva I.A., Chucanov V.I., Bagdasaryan T.R. et al. Effectiveness of the intensive phase of chemotherapy in pulmonary TB patients with primary drug resistance. Eur. Respir. J. 2006; 28 (Suppl. 50): 290.

50. Кононеи А.С., Мишин В.Ю., Голубева Л.И. и др. Сравнительная эффективность ІІБ и І режимов химиотерапии у впервые выявленных больных туберкулезом легких в пенитенциарных учреждениях с позиции медицины доказательств. Туберкулез и болезни легких. 2011; 4: 203-204. / Kononets A.S., Mishin V.Yu., Golubeva L.I. et al. Evidence-based comparison of efficacy of IIB vs I chemotherapeutic regimens in patients with newly diagnosed pulmonary tuberculosis in penitentiary settings. Tuberkulez i bolezni legkikh. 2011; 4: 203-204 (in Russian).

51. Мишин В.Ю., Левашов Ю.Н., Елькин А.В. и др. Многоцентровое рандомизированное клиническое исследование нового стандартного режима химиотерапии у впервые выявленных больных туберкулезом легких в регионах с высоким уровнем первичной множественной лекарственной устойчивости. В кн.: Материалы II Научно-практической конференции Москвы и Московского региона "Актуальные вопросы респираторной медицины". М.; 2010. 48-49. / Mishin V.Yu., Levashov Yu.N., El'kin A.V. et al. Multicenter randomised clinical trial of a new standard chemotherapeutic regimen in patients with newly diagnosed pulmonary tuberculosis in regions with high primary multi-drug resistance. In: Materials of the II Scientific and Practical Conference "Actual Issues of Respiratory Medicine" in Moscow and Moscow Region. 
[Materialy II Nauchno-prakticheskoy konferentsii Moskvy i Moskovskogo regiona "Aktual'nye voprosy respiratornoy meditsiny"]. Moscow; 2010: 48-49 (in Russian).

52. Мишин В.Ю., Мякишева Т.В., Мишина А.В. Эффективность различных методов введения противотуберкулезных препаратов во ІІБ режиме химиотерапии у впервые выявленных больных туберкулезом легких с позиций медицины доказательств. Практическая медицина. 2011; 3 (51): 63-67. / Mishin V.Yu., Myakisheva T.V., Mishina A.V. Efficacy of different routes of administration of IIB chemotherapeutic regimen anti-tuberculosis drugs according to evidence-based medicine. Prakticheskaya meditsina. 2011; 3 (51): 63-67 (in Russian).

53. Мишин В.Ю., Кононеи А.С., Мякишева Т.В. и др. Сравнительная эффективность ІІБ и I режимов химиотерапии у впервые выявленных больных деструктивным туберкулезом легких в гражданских и пенитенциарных противотуберкулезных учреждениях. Туберкулез и болезни легких. 2012; 4: 18-26. / Mishin V.Yu., Kononets A.S., Myakisheva T.V. et al. Comparative efficacy of IIB vs I chemotherapeutic regimens in patients with newly diagnosed cavitary pulmonary tuberculosis in penitentiary and civil settings. Tuberkulez i bolezni legkikh. 2012; 4: 18-26 (in Russian).

54. Мохирева Л. В., Каркач О.О. Комбинированный препарат Ломекомб в комплексной терапии туберкулеза. Туберкулез и болезни легких. 2011; 8: 44-50. / Mokhireva L.V., Karkach O.O. Combined drug Lomecomb in therapy of pulmonary tuberculosis. Tuberkulez i bolezni legkikh. 2011; 8: 44-50 (in Russian).

55. Мякишева T.B. Особенности течения и эффективность лечения туберкулеза легких с лекарственной устойчивостью возбудителя у лиц молодого возраста: Дисс. ... д-ра мед. наук. М.; 2013. / Myakisheva T.V. Particularities of Course and Therapeutic Efficacy of Multi-drug Resistant Pulmonary Tuberculosis in Young: Diss. Moscow; 2013 (in Russian)

56. Мишина А.В., Мишин В.Ю., Митрушкина В.И. и др. Индивидуальный и стандартный режимы химиотерапии у больных с впервые выявленным туберкулезом, сочетанным с ВИЧ-инфекцией, с позиций доказательной медицины в Российской Федерации. Пульмонология. 2013; 4: 43-50. / Mishina A.V., Mishin V.Yu., Mitrushkina V.I. et al. Personalized and standard chemotherapeutic regimens in HIV-infected patients with newly diagnosed pulmonary tuberculosis. Pul'monologiya. 2013; 4: 43-50 (in Russian).

57. Мишин В.Ю., Ерохин В.В., Тюляев И.И. и др. Комбинированный противотуберкулезный препарат Левофлорипин. (Патент № 2354378). Изобретения. Полезные модели. 2009; 13: 470-471. / Mishin V.Yu., Erokhin V.V., Tyulyaev I.I. et al. Combined anti-tuberculosis drug Levoflorilin. (Patent RF N 2354378). Izobreteniya. Poleznye modeli. 2009; 13: 470-471 (in Russian).

58. Мохирева Л.В. Эффективность применения комбинированных противотуберкулезных препаратов у больных впервые выявленным туберкулезом легких: Дисс. ... Д-ра мед. наук. М.; 2013. / Mokhireva L.V. Efficacy of Combined Anti-Tuberculosis Drugs in Patients with Newly Diagnosed Tuberculosis. Diss. Moscow; 2013 (in Russian).

59. Филиппов А.В., Мохирева Л.В., Иванушкина Т.Н. и др. Новый комбинированный противотуберкулезный препарат Левофлорипин в лечении впервые выявленного туберкулеза с распадом легочной ткани и бактериовыделением. Туберкулез и болезни легких. 2012; 9: 38-45.
/ Filippov A.V., Mokhireva L.V., Ivanushkina T.N. et al. The new combined anti-tuberculosis drug Levoflorilin in treatment of patients with newly diagnosed smear-positive cavitary pulmonary tuberculosis. Tuberkulez i bolezni legkikh. 2012; 9: 38-45 (in Russian).

60. Мишин В.Ю., Кононеи А.С., Голубева Л.И. Эффективность и переносимость нового стандартного режима химиотерапии с использованием фторхинолонов у впервые выявленных больных деструктивным туберкулезом легких. Русский медицинский журнал. 2007; 18 (299): 1302-1305. / Mishin V.Yu., Kononets A.S., Golubeva L.I. Efficacy and tolerability of a new standard chemotherapeutic regimen using fluoroquinolones in patients with newly diagnosed cavitary pulmonary tuberculosis. Russkiy meditsinskiy zhurnal. 2007; 18 (299): 1302-1305 (in Russian).

61. Васильева И.А., Эргешов А.Э., Самойлова А.Г. и др. Отдаленные результаты применения стандартных режимов химиотерапии у больных туберкулезом органов дыхания. Туберкулез и болезни легких. 2012; 4: 3-8. / Vasil'eva I.A., Ergeshov A.E., Samoylova A.G. et al. Long-term results of treatment patients with pulmonary tuberculosis using standard chemotherapeutic regimens. Tuberkulez i bolezni legkikh. 2012; 4: 3-8 (in Russian).

62. Самойлова А.Г., Васильева И.А., Иванов А.К. и др. Эффективность стандартных режимов химиотерапии туберкулеза в зависимости от лекарственной чувствительности возбудителя. Туберкулез и болезни легких. 2012; 8: 23-29. / Samoylova A.G., Vasil'eva I.A., Ivanov A.K. et al. Efficacy of standard anti-tuberculosis chemotherapeutic regimens according to drug resistance of the pathogen. Tuberkulez i bolezni legkikh. 2012; 8: 23-29 (in Russian).

63. Диагностика и лечение туберкулеза с множественной лекарственной устойчивостью возбудителя: Методические материалы к проведению цикла тематического усовершенствования врачей Американского международного союза здравоохранения при поддержке Агентства США по международному развитию и ФГБУ ЦНИИТ РАМН. М.: Valent Publishing House; 2012. / Diagnosis and Treatment of Multi-drug Resistant Tuberculosis: Methodological Guidelines for Postgraduate Course of the American International Health Alliance, U.S.Agency for International Development and the Central Tuberculosis Scientific and Research Institute of Russian Medical Academy. [Diagnostika i lechenie tuberkuleza s mnozhestvennoy lekarstvennoy ustoychivost'yu vozbuditelya: Metodicheskie materialy k provedeniyu tsikla tematicheskogo usovershenstvovaniya vrachey Amerikanskogo Mezhdunarodnogo Soyuza Zdravookhraneniya Agentstva SShA po Mezhdunarodnomu razvitiyu i FGBU TsNIIT RAMN]. Moscow: Valent Publishing House; 2012 (in Russian).

64. Бастиан И., Порталс Ф. Туберкулез с множественной лекарственной устойчивостью: Пер. с англ. М.; 2003. / Bastian I., Portals F. Multi-drug resistant tuberculosis (Translated from English) [Tuberkulez s mnozhestvennoy lekarstvennoy ustoychivost'yu]: Per. s angl. Moscow; 2003 (in Russian).

65. Мишин В.Ю., Дейкина О.Н., Назарова Н.А. и др. Влияние неспецифических антимикробных препаратов (амоксициллин / клавунат, кларитромицин и имипенем / циластин) на течение туберкулеза легких. Пульмонология. 2013; 5: 45-48. / Mishin V.Yu., Deykina O.N., Nazarova N.A. et al. Effects of non-specific antibiotics (amoxicillin / clavulanate, clarythromycin, imipenem / cilastatin) on the course of pulmonary tuberculosis. Pul'monologiya. 2013; 5: 45-48 (in Russian). 
66. Макаров А.А., ред. Выявление микобактерий туберкулеза и определение лекарственной устойчивости с использованием биологических чипов: Методическое пособие. М.; 2009. / Makarov A.A., ed. Detection of Mycobacterium Tuberculosis and its Drug Resistance Using Biological Chips: Methodological Handbook. [Vyyavlenie mikobakteriy tuberkuleza i opredelenie lekarstvennoy ustoychivosti s ispol'zovaniem biologicheskikh chipov. Metodicheskoe posobie]. Moscow; 2009 (in Russian).

67. Дауров Р.Б., Васильева И.А., Перфильев А.В. и др. Клинико-рентгенологическая динамика у впервые выявленных больных туберкулезом легких с множественной лекарственной устойчивостью микобактерий при раннем назначении резервной схемы химиотерапии по данным тест-системы "ТБ-Биочип". Туберкулез и болезни легких. 2011; 4: 10-13. / Daurov R.B., Vasil'eva I.A., Perfil'ev A.V. et al. Clinical and radiological evaluation with the TB-Biochip test following early administration of the second-line chemotherapy in patients with newly diagnosed multi-drug resistant pulmonary tuberculosis. Tuberkulez i bolezni legkikh. 2011; 4: 10-13 (in Russian).
68. Мишин В.Ю. Сравнительная эффективность IІБ и IV режима химиотерапии у впервые выявленных больных с множественной лекарственной устойчивостью возбудителя, выявленной по данным тест-системы "Биочип-ТБ". В кн.: Сборник тезисов ХІХ Российского национального конгресса "Человек и лекарство". М.; 2012: 318. / Mishin V.Yu. Comparative efficacy of IIB vs IV chemotherapeutic regimens in patients with newly diagnosed multi-drug resistant tuberculosis according to results of the TB-Biochip test. In: The XIX Russian National Congress "A Human and a Medicine" Proceedings. [Sbornik tezisov XIX Rossiyskogo natsional'nogo kongressa "Chelovek i lekarstvo"]. Moscow; 2012: 318 (in Russian).

\section{Информация об авторе}

Мишин Владимир Юрьевич - д. м. н., профессор, зав. кафедрой фтизиопульмонологии ГБОУ ВПО "МГМСУ им. А.И.Евдокимова", заслуженный врач РФ; тел.: (910) 436-56-88; e-mail: mishin.vy@mail.ru

Поступила 15.04.14 (С) Мишин В.Ю., 2014 удк 616.24-002.5-085-281(470) 